\title{
Design of Switched Mode Power Supply using FPGA Based Fuzzy Logic Controller
}

\author{
R. Anusha ${ }^{1}$, A. Majitha Farven ${ }^{2}$, M. Radhika ${ }^{3}$, G. Susmitha ${ }^{4}$, Mrs. Chitravalavan M.Tech., (Ph.D.), ${ }^{5}$ \\ UG Student, Department of Electronics and Communication Engineering, A.V.C College of Engineering, \\ Mayiladuthurai, India ${ }^{1,2,3,4}$ \\ Professor, Department of Electronics and Communication Engineering, A.V.C College of Engineering, \\ Mayiladuthurai, India ${ }^{5}$
}

\begin{abstract}
This paper presents a fuzzy logic controller (FLC) model for buck converter topology of Switched Mode Power Supply (SMPS).In order to obtain the improved voltage regulation in SMPS, we use digital control using FLC which significantly more efficient than analog control. FLC maintains a constant or fixed output voltage irrespective of variations in input voltage. In this paper, Buck converter used in SMPS converts the input voltage to a desired voltage. The very high speed integrated circuit hardware description language (VHDL) Coding of fuzzy logic is dumped into Field Programmable Gate Array (FPGA).Fuzzy Logic compares obtained voltage with the threshold value by applying feedback control. FPGA is the most important tool for hardware implementation due to low consumption of energy, high speed of operation and large capacity of data storage. FPGA generates Controlled Pulse Width Modulation (PWM) pulses of required duty cycle which produce gating signals to MOSFETs of buck converters to maintain the required constant output voltages. The controller algorithm is developed using Xilinx ISE 12.0 and is implemented on FPGA Spartan 3AN
\end{abstract}

Keywords: Buck Converter; Field Programmable Gate Array (FPGA); Fuzzy Logic Controller (FLC); Pulse Width Modulation (PWM).

\section{INTRODUCTION}

Switched Mode Power Supply (SMPS) is the most switching pulse. The pulse width is varied with the prevailing architecture for DC power supply in modern changes in the DC output voltage level, this change in the systems, primarily for its capability to handle variable pulse width cancels the output voltage change and the loads. In this design the line voltage at $230 \mathrm{~V} / 50 \mathrm{~Hz}$ is taken SMPS output remains constant irrespective of load as input, this voltage is stepped down to $12 \mathrm{~V}$, rectified and variations level.

passed through filter capacitor to give an unregulated DC voltage. The unregulated dc voltage across the capacitor is then fed to a high frequency dc-to-dc buck converters. These Converters step down the $12 \mathrm{~V}$ input to $5 \mathrm{~V}$ and $3.3 \mathrm{~V}$ which may have some voltage fluctuations. Inorder to obtain an accurate output voltages $5 \mathrm{~V}$ and $3.3 \mathrm{~V}$, the obtained voltage is given to Analog to Digital Converter (ADC), as the FPGA with Fuzzy Logic controller generates PWM pulse by comparing digital signals from feedback with the predefined threshold value. FPGA generates Controlled PWM pulses of required duty cycle which produce gating signals to MOSFETs of buck converters to maintain the required constant output voltages. The SMPS circuit, having a power MOSFET for switching operation and a PWM based Feedback circuit for driving the switching of the MOSFET is designed. This unregulated voltage is chopped using a MOSFET switch, driven by PWM feedback signal, to control the output voltage. The feedback network generates a high frequency PWM signal to drive the MOSFET switch. The $\mathrm{dc}$ voltage at the output depends on the width of the

\section{DIGITAL CONTROL APPROACHES}

Fig. 1 shows block diagram of digital controlled SMPS. Analog output voltage feedback signal is converted into digital values by using ADC so that it can be processed by digital controller (Fuzzy logic). Digital value of feedback voltage is subtracted from reference voltage value which is known as error signal input for digital controller. In case of digital control block reference voltage is fixed constant value in a program which is unaffected by variations in temperature. Result of subtraction is digital count equivalent to error voltage and PWM output is function of error voltage this can be controlled by fuzzy logic control. FPGA generates PWM signals to buck converter. The hardware implementation of SMPS using digital control techniques is done. Output voltage produced by SMPS is digitized using analog to digital converter with the help of ADC. Analog to digital converter is a device that converts analog input to digital number proportional to the magnitude of analog input. 


\section{International Journal of Innovative Research in Electrical, Electronics, Instrumentation and Control Engineering}

\section{ISO 3297:2007 Certified}

Vol. 5, Issue 3, March 2017

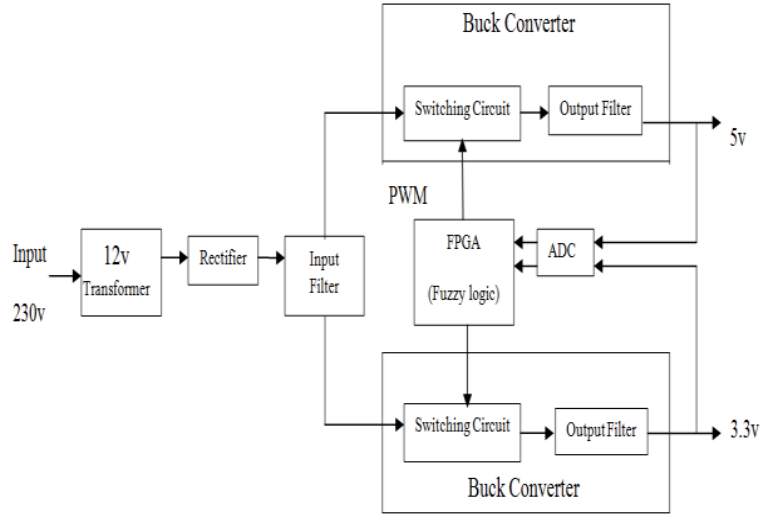

Fig.1 Block diagram of digital controlled SMPS

knowledge, expressed as linguistic variables, while the membership functions represent expert interpretation of those variables.

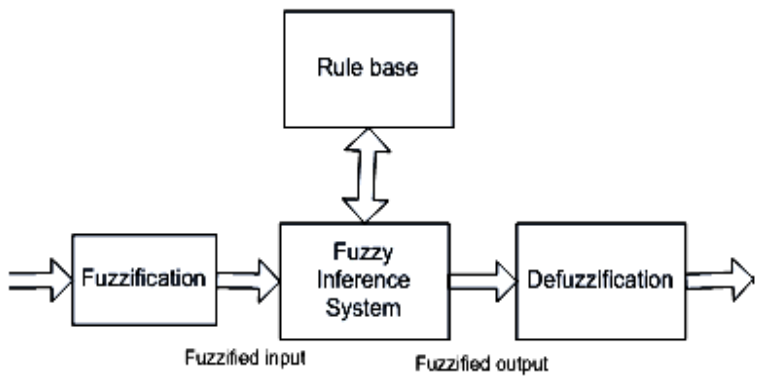

Fig.2 Block diagram of a fuzzy control system

The resolution of ADC is the number of discrete values it can produce over the range of analog input. Eight bit resolution $\mathrm{ADC}$ can output numbers in the range of 0 to 255 , so that it can process by digital circuitry.

This digitized voltage is subtracted from reference voltage .Output of ADC is used at feedback voltage, this feedback voltage is subtracted from reference voltage which is constant such that error signals will get same span in positive as well as negative side. This error will act as input to Fuzzy controller. Coefficients of fuzzy controller are tuned by dumping as VHDL coding to FPGA through Xilinx software, which result duty cycle limit is assigned to on period. In case of negative values on period kept zero. This ensured maximum PWM limit so components will not be getting damaged because of excessive PWM.

\subsection{Fuzzy Logic}

Fuzzy logic is a logic having many values, approximate reasoning and have a vague boundary. The variables in fuzzy logic system may have any value in between 0 and 1 and hence this type of logic system is able to address the values of the variables (called linguistic variables) those lie between completely truths and completely false. Each linguistic variable is described by a membership function which has a certain degree of membership at a particular instance. The human knowledge is incorporated in fuzzy rules. The fuzzy inference system formulates suitable rules and based on these rules the decisions are made. This whole process of decision making is mainly the combination of concepts of fuzzy set theory, fuzzy IFTHEN rules and fuzzy reasoning. The fuzzy inference system makes use of the IF-THEN statements and with the help of connectors present (such as OR and AND), necessary decision rules are constructed. The fuzzy rule base is the part responsible for storing all the rules of the system and hence it can also be called as the knowledge base of the fuzzy system. Fuzzy inference system is responsible for necessary decision making for producing a required output. The fuzzy control systems are rule-based systems in which a set of fuzzy rules represent a control decision mechanism for adjusting the effects of certain system stimuli. The rule base reflects the human expert

A fuzzy logic controller is composed of the following four elements:

1. A rule-base (a set of If-Then rules), which contains a fuzzy logic quantification of the expert's linguistic description of how to achieve good control.

2. An inference mechanism (also called an "inference engine" or "fuzzy inference" module), which emulates the expert's decision making in interpreting and applying knowledge about how best to control the plant.

3. A fuzzification interface, which converts controller inputs into information that the inference mechanism can easily use to activate and apply rules.

4. A defuzzification interface, which converts the conclusions of the inference mechanism into actual inputs for the process.

The crisp inputs are applied to the input side of fuzzification unit. The fuzzification unit converts the crisp input into fuzzy variable. The fuzzy variables are then passed through the fuzzy rule base. The fuzzy rule base computes the input according to the rules and gives the output. The output is then passed through defuzzification unit where the fuzzy output is converted into crisp output.

\subsubsection{PWM Concepts}

PWM or Pulse Width Modulation is the modulation technique where frequency and Amplitude of the pulse signal is not varied and the pulse width or the duty cycle is varied to encode the information. A common use of PWM is to control the average current or Voltage input to a device. In this project the PWM Signal is generated as feedback control signal for driving the switching of the MOSFET switch. The output Voltage is taken and converted into digital signal using ADC.The pulse width of the PWM is determined by comparing the digital value with the predefined threshold value given through VHDL coding. The switching period determines the voltage at the output. Thus if there is any change at the output Voltage, the corresponding change in the PWM pulse width will nullify its effect and the output voltage will be restored to desired value. 
Vol. 5, Issue 3, March 2017

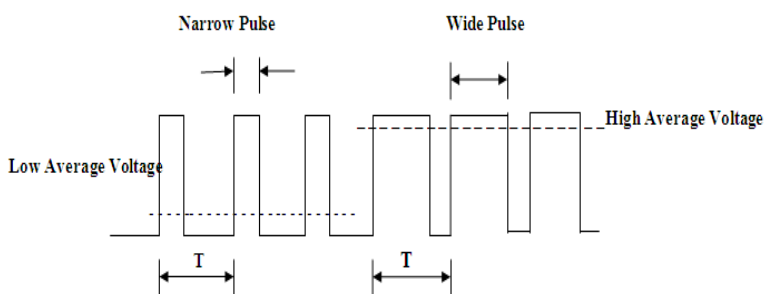

Fig.3 pulse width modulation

A switch-mode converter varies its dc output current in response to load changes. One widely-used approach is pulse width modulation (PWM) that controls the power switch output power by varying its $\mathrm{ON}$ and OFF times. The ratio of ON time to the switching period time is the duty cycle. The duty cycle is adjusted to regulate the output voltage.

\subsubsection{FPGA Technology}

A Field Programmable Gate Array (FPGA) is a reconfigurable digital integrated circuit that can be programmed in order to perform any digital function. FPGA device is greatly used to control power electronic systems. The language known as Very High Hardware Description Language (VHDL) is used to program this device.

\section{FUZZY LOGIC MEMBERSHIP FUNCTION}

The buck dc-dc converter is a nonlinear function of the duty cycle because of the small signal model and its control method was applied to the control of buck converters. In Fuzzy controllers mathematical model is not require. Instead, they are designed based on general knowledge of the buck converter. The Fuzzy controllers are designed to adopt the varying operating points. Fuzzy Logic Controller is designed to control the output of buck dc-dc converter. In the fuzzy logic system two input variables, error (e) and change of error (de) and one output variable $(\mathrm{u})$ is duty cycle of PWM output are used. For each input and output variable fuzzy sets must be defined.

As shown in Fig.4. The five fuzzy subsets PS (Positive Small), PB(Positive Big), ZE (Zero), NS (Negative Small), NB (Negative Big) have been chosen for input variables error (e) and change of error (de). The Triangular shape has been adopted for the membership functions; the value of each input and output variable is normalized in the range $[-1,1]$ by using suitable scale factors.

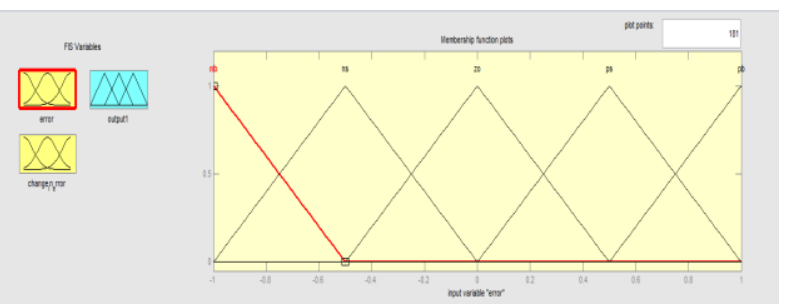

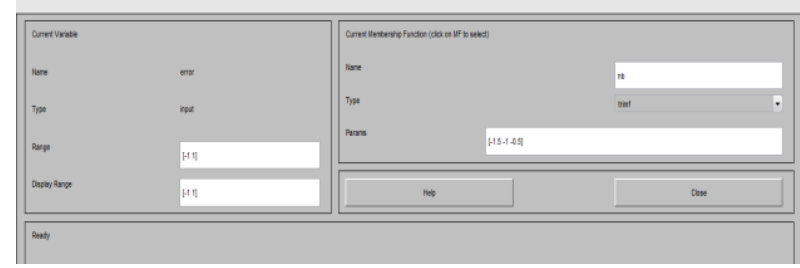

Fig.4 The Membership Function plots of error

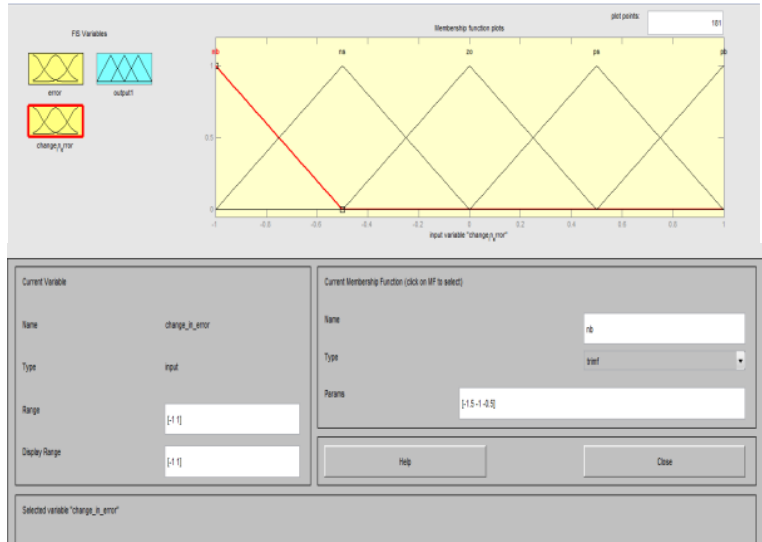

Fig.5 The Membership Function plots of change error

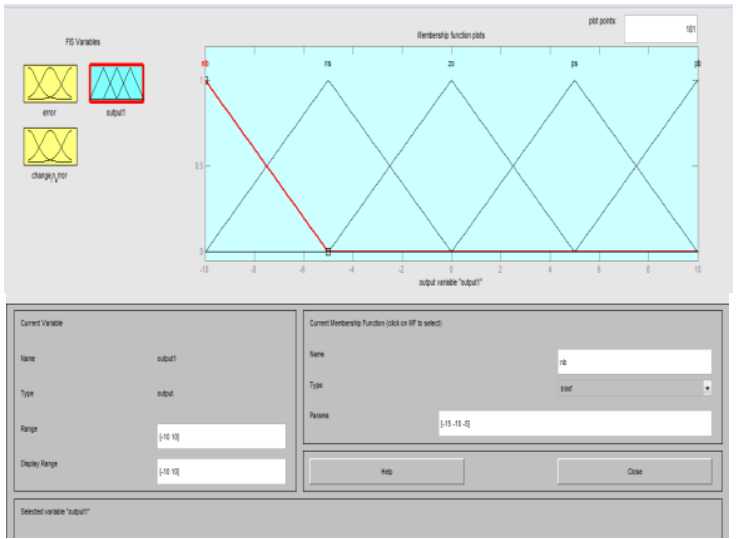

Fig.6 The Membership Function plots of duty ratio

\subsection{Fuzzy Logic Table Rules:}

Fuzzy controller rules which are play a very important role for controller simulation are obtained from the analysis of the system behavior. In their formulation it must be considered that, by using this controller we improve the converter performances in terms of regulate the constant voltage.

\begin{tabular}{|c|c|c|c|c|c|}
\hline$(\mathrm{de})$ & NB & NS & ZO & PS & PB \\
\hline NB & NB & NB & NB & NS & ZO \\
\hline NS & NB & NB & NS & ZO & PS \\
\hline ZO & NB & NS & ZO & PS & PB \\
\hline PS & NS & ZO & PS & PB & PB \\
\hline PB & ZO & PS & PB & PB & PB \\
\hline
\end{tabular}

Table. 1 rules for error and change of error 


\section{International Journal of Innovative Research in Electrical, Electronics, Instrumentation and Control Engineering}

\section{ISO 3297:2007 Certified}

Vol. 5, Issue 3, March 2017

When the output voltage is far from the set point i.e error(e) is NB or PB, the controller must be do the strong corrective action i.e duty cycle close to zero or have the dynamic response as fast as possible, obviously taking into account current limit specifications of the system.

Second, when output voltage error of the system approaches to zero i.e error (e) is ZE, NS, PS then in order to ensure stability around the working point, the current error should be properly taken into account. when the current value approaches the limit value, suitable rules must be introduced to preventing the large overshoots. The rules of fuzzy control for error and change of error can be referred in the table 1 .

\subsubsection{Simulation Results:}

The simulink model of buck converter with fuzzy logic controller is shown in Fig.7 and simulation is carried out in MATLAB/SIMULINK.

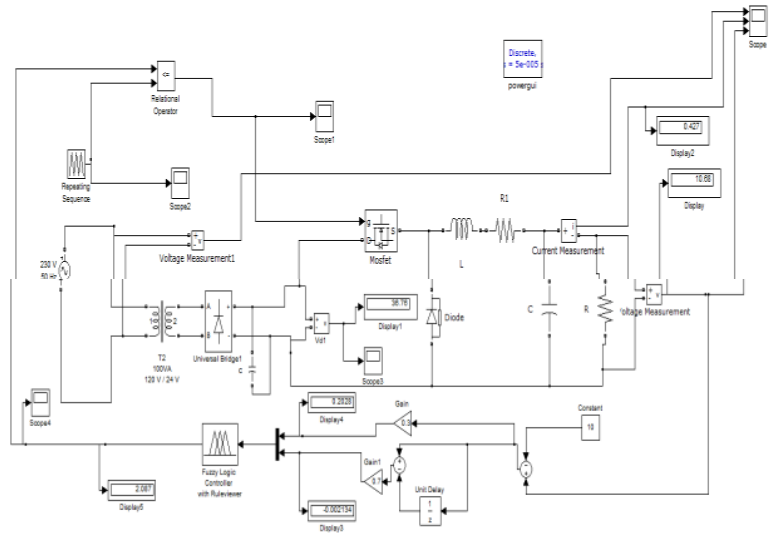

Fig.7 Closed loop simulink model of Buck converter using Fuzzy logic Controller

Simulation is done with the variation in input voltage $230 \mathrm{~V}$ at different loads maintaining output voltage constant at $5 \mathrm{~V}$ and $3.3 \mathrm{~V}$.

\section{CONCLUSION}

In this paper we presented design and implementation of the digital based fuzzy logic control on FPGA. Digital control was successfully implemented and developed for the desktop computer system. Application of FPGA structure is very suitable for high speed processes and we presented in this paper the basic necessary principles how to realize fuzzy logic cont control algorithms. We scheduled this approach for the predictive control and soft computing methods.

\section{REFERENCES}

[1] Puspendu Maji, Prof. G K. Panda, Prof. P K. Saha (2015) "Performance Analysis for DC-DC Buck Converter with Fuzzy and Robust Controller" International Journal of Advanced Research in
Electrical, Electronics and Instrumentation Engineering, Vol. 4, Issue. 5, pp.4127-4135

[2] Rajesh Kr Ahuja and Rajesh Kumar.(2014)," Design and Simulation of Fuzzy Logic Controller based Switched-Mode Power Supply" IPASJ International Journal of Electrical Engineering (IIJEE),Vol. 2, Issue 5,pp. 16-21.

[3] Aung Myaing, Venkata Dinavahi (2011), "FPGA-based real-time emulation of power electronic systems with detailed representation of device characteristics", IEEE transactions on industrial electronics, Vol. 58, No. 1, pp. 358-368.

[4] Chia-An Yeh, Yen-Shin Lai(2012), "Digital pulsewidth modulation technique for a synchronous buck $\mathrm{dc} / \mathrm{dc}$ converter to reduce switching frequency", IEEE Transactions on industrial electronics, Vol.59,No.1,pp 550-561.

[5] Shubhangi V. Patil, Tejashree R. Shukla,"Modeling of PID controller based SMPS using FPGA" International Journal of Innovative Research in Science, Engineering and Technology.

[6] Fathi Shaban Jabber, (2011), "Development of a DC-DC BuckBoost Converter Using Fuzzy Logic Control", Master of Electrical Engineering Thesis, University Tun Hussein Onn, Malaysia, pp. 135

[7] N.J.Ham C.J.Hammerton D.Sharples " Switched Mode Power Supplies" Power Semiconductor Applications Philips Semiconductor, pp. 103-240. 